\title{
Suppression of Electrostatic Mediated Antibody Liquid-Liquid Phase Separation by Charged and Non-Charged Preferentially Excluded Excipients
}

\author{
Douglas D. Banks ${ }^{1 *}$ and Jon F. Cordia ${ }^{1}$
}

${ }^{1}$ Department of Pharmaceutical Candidate Optimization, Bristol Myers Squibb, 4242 Campus Point Ct Suite 700, San Diego, CA 92121

Figure S1. The cooling rate dependence of LLPS monitored at $600 \mathrm{~nm}$ using a 10 $\mathrm{mg} \cdot \mathrm{mL}^{-1} \mathrm{mAb}-\mathrm{B}$ solution buffered at $\mathrm{pH}$ 7.0 by $10 \mathrm{mM} \mathrm{KPi}$. No change in $\mathrm{C}_{\mathrm{T}}$ (red dashed line) was observed for cooling rates less than $0.5^{\circ} \mathrm{C} \cdot \mathrm{min}^{-1}$, therefore a cooling rate of $0.2{ }^{\circ} \mathrm{C} \cdot \mathrm{min}^{-1}$ was used throughout this investigation.

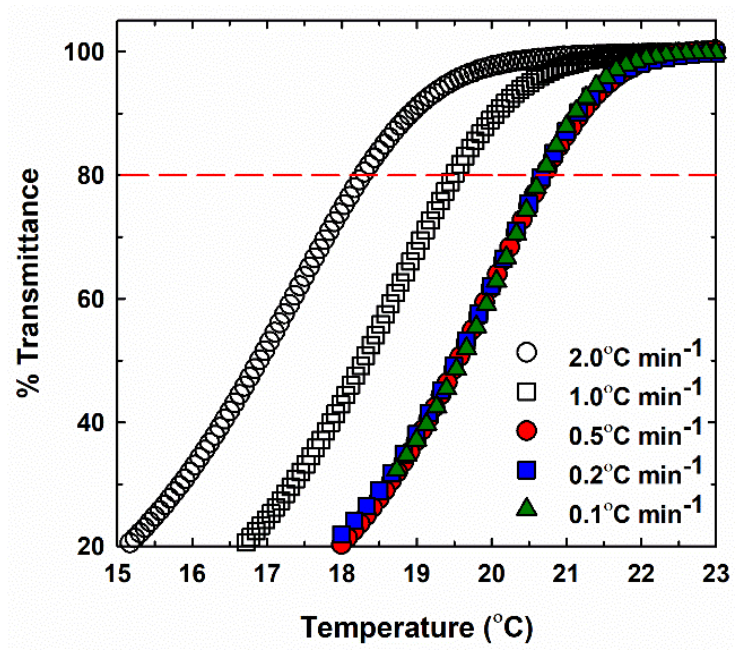

\section{Size Exclusion Chromatography and Multi Angle Static Light Scattering}

Size Exclusion Chromatography (SEC) was performed on an Agilent 1200 series quaternary pump liquid chromatography system (Palo Alto, CA); $50 \mu \mathrm{g}$ of mAb-B was injected neat onto a single TosoHaas TSK-gel SW3000xl column and eluted isocratically at a flow rate of 1.0 $\mathrm{mL} \cdot \mathrm{min}^{-1}$ using a mobile phase consisting of $100 \mathrm{mM}$ sodium phosphate $(\mathrm{pH} 7.0)$ and $150 \mathrm{mM}$ 
sodium chloride, absorbance was monitored at $280 \mathrm{~nm}$. The static light scattering intensities and concentrations of the mAb-B species eluting from SEC were monitored using a Wyatt Technology DAWN HELEOS II multi angle light scattering (MALS) detector equipped with at $658 \mathrm{~nm}$ laser (Santa Barbara, CA) in combination with an Wyatt Technology Optilab T-rEX refractometer (Santa Barbara, CA) using a differential refractive index of $0.185 \mathrm{~mL} / \mathrm{g}$. The molar masses were determined by fitting the protein concentration dependence of the excess Rayleigh ratio to the Zimm equation using the procedures given elsewhere. ${ }^{1}$

Figure S2. Representative SEC chromatogram (A) and SEC-MALS (B) of mAb-B. The SECMALS data indicates that the low percentage of mAb-B high molecular weight species consists almost entirely of dimer. Note that the flow rate was decreased to $0.5 \mathrm{~mL} \cdot \mathrm{min}^{-1}$ to improve resolution for the SEC-MALS experiments.
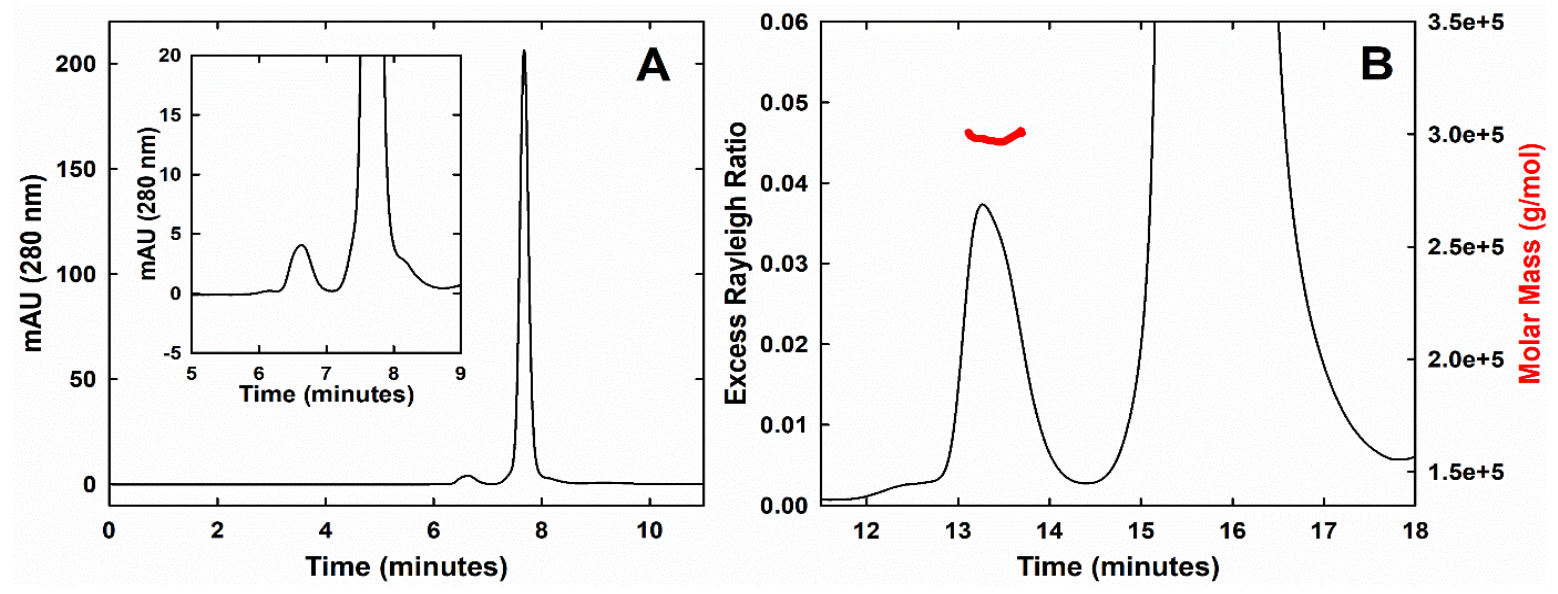

\section{Molarity to Molality Conversion}

The non-mAb-B and $\mathrm{mAb}-\mathrm{B}$ containing excipient dilution series were converted from molar to molal concentrations using eq $\mathrm{S} 1$ and $\mathrm{S}_{2}^{2}$ and the partial molar volumes $(\bar{V})$ of each of the excipients, water $\left(0.01807 \mathrm{~L} \cdot \mathrm{mol}^{-1}\right)$ and $\mathrm{mAb}-\mathrm{B}$. Here, $\mathrm{i}$ is the solute of interest (excipient or $\mathrm{mAb}-\mathrm{B})$ and the subscript 1 refers to water. For the $\mathrm{mAb}-\mathrm{B}$ containing solutions $\mathrm{j}$ refers to the third solute (excipient or mAb-B). The partial molar volumes of the excipients were taken from the literature ${ }^{2-4}$ and an estimated partial molar volume of $108.3 \mathrm{~L} \cdot \mathrm{mol}^{-1}$ was used for $\mathrm{mAb}-\mathrm{B}$. 


$$
\begin{gathered}
\mathrm{m}_{\mathrm{i}}=\frac{[\mathrm{i}]}{\mathrm{m}_{1} \overline{\mathrm{V}}_{1}-[\mathrm{i}] \overline{\mathrm{V}}_{\mathrm{i}}} \\
\mathrm{m}_{\mathrm{i}}=\frac{[\mathrm{i}]}{\mathrm{m}_{1} \overline{\mathrm{V}}_{1}-[\mathrm{i}] \overline{\mathrm{V}}_{\mathrm{i}}-[\mathrm{j}] \overline{\mathrm{V}}_{\mathrm{j}}}
\end{gathered}
$$

Figure S3. Osmolality data collected by VPO as a function of $\mathrm{Arg}-\mathrm{HCl}(\mathrm{A})$, proline (B), sucrose (C), sorbitol (D), glycerol (E) and urea (F) molality in non-mAb-B (open symbols) and 75 $\mathrm{mg} \cdot \mathrm{mL}^{-1} \mathrm{mAb}-\mathrm{B}-$ containing solutions (closed symbols) buffered at $\mathrm{pH} 7.0$ with $10 \mathrm{mM} \mathrm{KPi}$. Error bars are generally smaller than the symbols and represent the standard deviation of the average of a minimum of triplicate independent measurements. These errors were used to weight the fits (lines) of the Arg- $\mathrm{HCl}$ VPO data to a quadratic equation and the remaining excipient VPO data to linear equations.
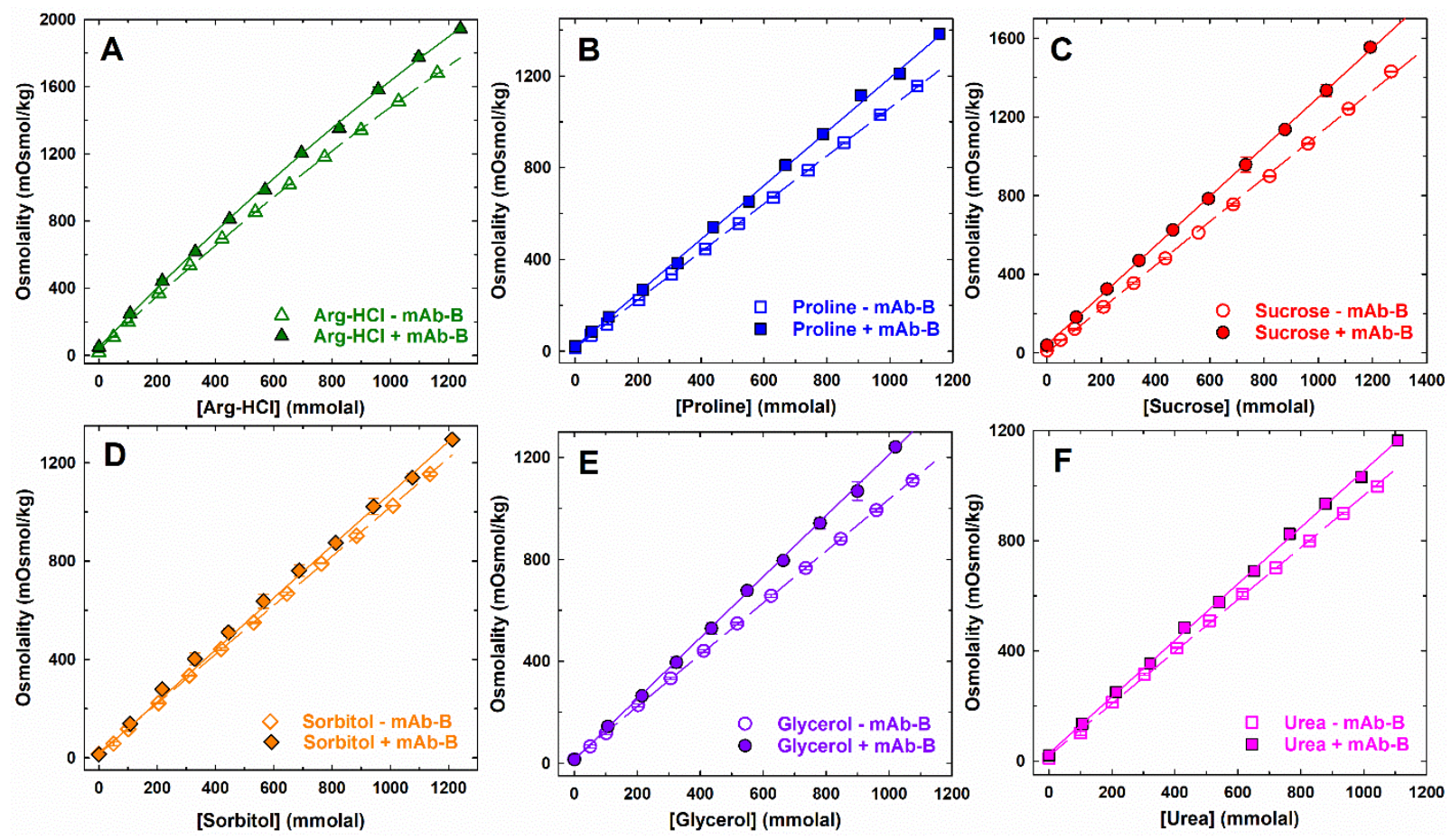
Figure S4. DSC thermograms of $1 \mathrm{mg} \cdot \mathrm{mL}^{-1} \mathrm{mAb}-\mathrm{B}$ solutions buffered at $\mathrm{pH} 7.0$ with $10 \mathrm{mM}$ $\mathrm{KPi}$ in the absence of excipient (A) and in the presence of $1 \mathrm{M}$ proline (B), $1 \mathrm{M} \mathrm{Arg}-\mathrm{HCl}$ (C), 1 $\mathrm{M}$ sucrose (D), $1 \mathrm{M}$ sorbitol (E), $1 \mathrm{M}$ Glycerol (F) and $1 \mathrm{M}$ urea (G). The buffer subtracted and normalized data are shown in black and the cumulative fits of each thermogram to three Gaussian peaks are shown in red. Based on thermal unfolding transitions identified for similar IgG1 mAbs, ${ }^{5,6}$ we tentatively assigned the endotherm with the largest enthalpy of unfolding as the Fab and the endotherm with the lowest $\mathrm{T}_{\mathrm{m}}{ }^{\text {app }}$ of the remaining two unfolding transitions as the $\mathrm{C}_{\mathrm{H}} 2$ domain (Table 1).
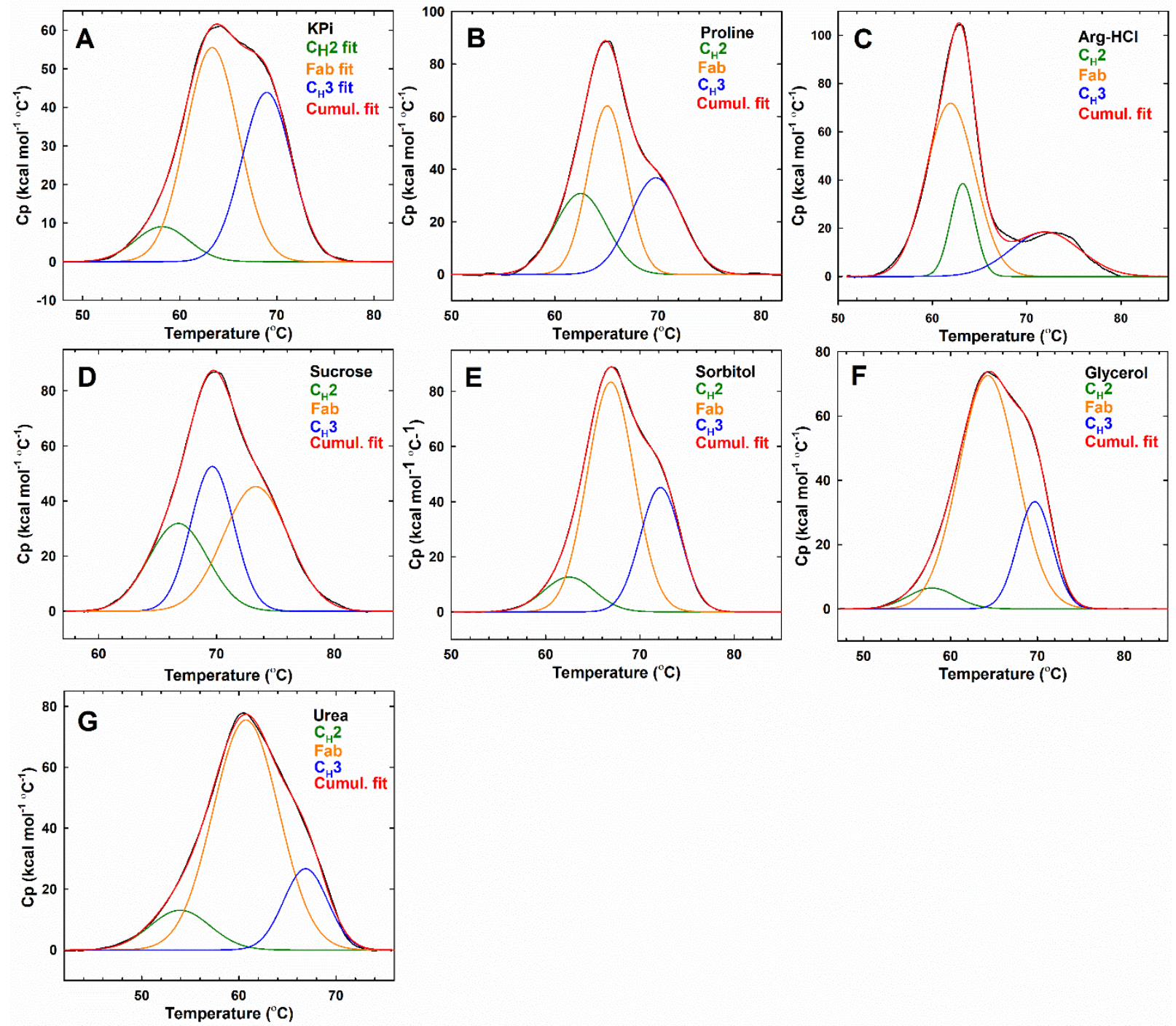
Figure S5. Native-State mAb-B preferential interaction parameters (A) and transfer free energies (B) derived from the VPO experiments using eqs 2,3 and 5. Conditions: $75 \mathrm{mg} \cdot \mathrm{mL}^{-1}$ $\mathrm{mAb}-\mathrm{B}, 10 \mathrm{mM} \mathrm{KPi}(\mathrm{pH} 7.0)$. Note that although it is energetically unfavorable to transfer the mAb-B native-state from water to urea (B) the fact that it acts as a denaturant (Table 1) indicates that transfer of the mAb-B unfolded-state into urea must be less energetically unfavorable.
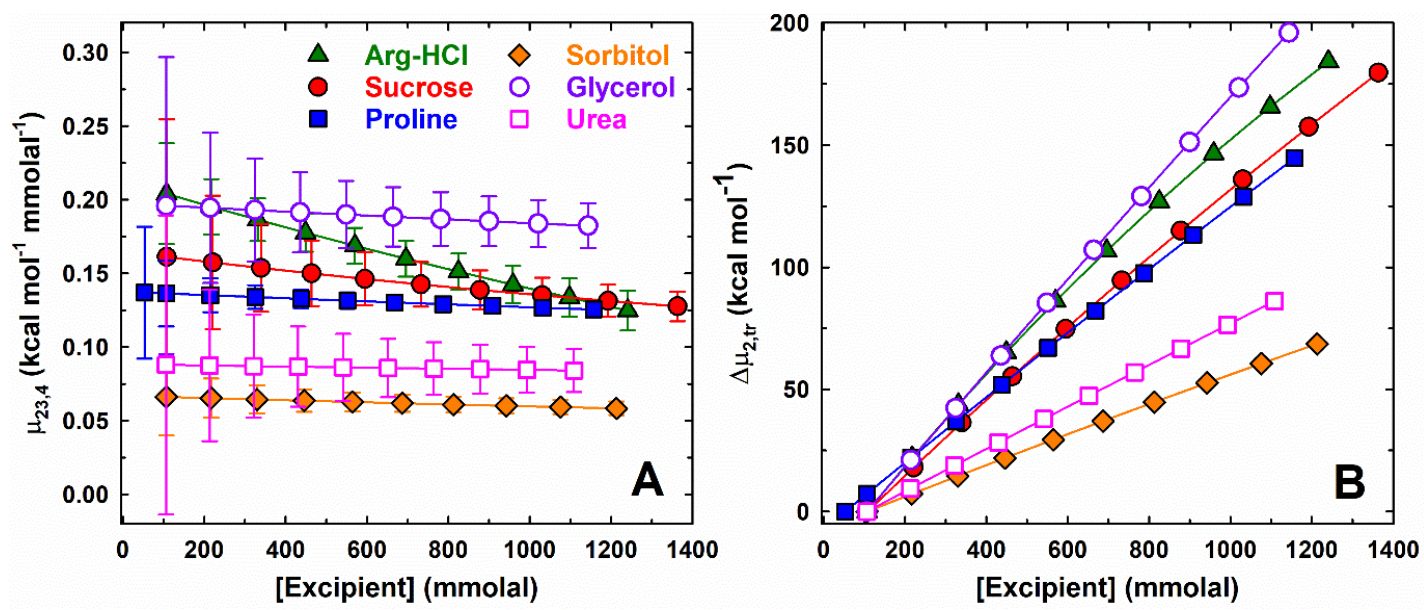

\section{References}

1. Wyatt, P. J., Light scattering and the absolute characterization of macromolecules. Analytica Chimica Acta 1993, $272(1), 1-40$.

2. Courtenay, E. S.; Capp, M. W.; Anderson, C. F.; Record, M. T., Vapor Pressure Osmometry Studies of Osmolyte-Protein Interactions: Implications for the Action of Osmoprotectants in Vivo and for the Interpretation of "Osmotic Stress" Experiments in Vitro. Biochemistry 2000, 39 (15), 4455-4471.

3. Schneider, C. P.; Trout, B. L., Investigation of Cosolute-Protein Preferential Interaction Coefficients: New Insight into the Mechanism by Which Arginine Inhibits Aggregation. The Journal of Physical Chemistry B 2009, 113 (7), 2050-2058.

4. Auton, M.; Bolen, D. W.; Rösgen, J., Structural thermodynamics of protein preferential solvation: Osmolyte solvation of proteins, aminoacids, and peptides. Proteins: Structure, Function, and Bioinformatics 2008, 73 (4), 802-813.

5. Garber, E.; Demarest, S. J., A broad range of Fab stabilities within a host of therapeutic IgGs. Biochemical and Biophysical Research Communications 2007, 355 (3), 751-757.

6. Ionescu, R. M.; Vlasak, J.; Price, C.; Kirchmeier, M., Contribution of Variable Domains to the Stability of Humanized IgG1 Monoclonal Antibodies. Journal of Pharmaceutical Sciences 2008, 97 (4), 1414-1426. 